\title{
Successful Physician Training Program for Large Scale EMR Implementation
}

\author{
J.L. Pantaleoni1 ${ }^{1,2}$; L.A. Stevens ${ }^{1,2}$; E.S. Mailes ${ }^{2}$; B.A. Goad2 ; C.A. Longhurst ${ }^{1,2}$ \\ ${ }^{1}$ Department of Pediatrics, Stanford University School of Medicine, Stanford, California; \\ 2Department of Clinical Informatics, Stanford Children's Health, Palo Alto, California
}

\section{Keywords}

Physician, education, electronic medical records

\section{Summary}

End-user training is an essential element of electronic medical record (EMR) implementation and frequently suffers from minimal institutional investment. In addition, discussion of successful EMR training programs for physicians is limited in the literature. The authors describe a successful physician-training program at Stanford Children's Health as part of a large scale EMR implementation. Evaluations of classroom training, obtained at the conclusion of each class, revealed high physician satisfaction with the program. Free-text comments from learners focused on duration and timing of training, the learning environment, quality of the instructors, and specificity of training to their role or department. Based upon participant feedback and institutional experience, best practice recommendations, including physician engagement, curricular design, and assessment of proficiency and recognition, are suggested for future provider EMR training programs. The authors strongly recommend the creation of coursework to group providers by common workflow.

\section{Correspondence to:}

Julie L. Pantaleoni, MD

Department of Pediatrics

Stanford University School of Medicine

Stanford, California

Email: julie.pantaleoni@stanford.edu
Appl Clin Inform 2015; 6: 80-95

http://dx.doi.org/10.4338/ACI-2014-09-CR-0076

received: September 28, 2014

accepted: January 1, 2015

published: February 11, 2015

Citation: Pantaleoni JL, Stevens LA, Mailes ES, Goad $B A$, Longhurst CA. Successful physician training program for large scale EMR implementation. Appl Clin Inf 2015; 6: 80-95

http://dx.doi.org/10.4338/ACl-2014-09-CR-0076 


\section{Background}

Deliberate and comprehensive end-user training is essential for the implementation, actualization, and end-user satisfaction with an organization's chosen electronic medical record (EMR) [1-7]. Given the variety of roles and specialized workflows performed by medical staff, physicians comprise a unique group of end-users for whom distinct recommendations are essential. However, there are few guidelines in the literature addressing the development and implementation of an EMR training program for physicians. Rockswold et al, found that $43 \%$ of clinician users rated initial training as "less than adequate," $94.6 \%$ of respondents thought their ability to use the EMR could be improved, and the authors called for the closer study of both training content and delivery [8]. A review of the literature reveals general training strategies for all employees [9], recommendations for nursing populations [10], post-implementation training [11], training within the broader context of a successful EMR implementation [3, 6, 12, 13], and training as a barrier to EMR adoption [14, 15]. To our knowledge, this is the first manuscript to describe the focused development and implementation of a successful physician training program in preparation for a large scale EMR implementation.

\section{Case Report}

This case report outlines a training program developed at Stanford Children's Health (SCH). SCH includes Lucile Packard Children's Hospital (LPCH), the major teaching hospital for pediatric and obstetric care for Stanford University, as well as about 100 network physicians in a medical foundation. As of 2014, LPCH has 311 beds, approximately 1,250 faculty and advanced practice providers (APPs), and approximately 1,000 rotating fellows and residents. The EMR implementation at SCH was a transition from one commercially available EMR system to another. The legacy system included computerized physician order entry (CPOE) and online clinical documentation in the inpatient setting with partial adoption of online clinical documentation and no CPOE in the outpatient setting [16-19]. The newly procured software system was already in place at the physically adjacent but financially and operationally independent adult hospital Stanford Health Care for over five years at the time of implementation [20].

\subsection{Training Program Scope and Structure}

The scope of the project was to train all SCH credentialed providers to use the new EMR for their respective workflows; including faculty, community physicians, APPs, fellows, and residents. The training team consisted of eight instructional designers (IDs) who were each responsible for the training content, training environment creation, and education of the end-user trainers for their given application (e.g. ambulatory, inpatient, radiology etc.). The IDs also worked closely with the appropriate application team to understand the technical development of each workflow and to provide usability feedback from a learner's perspective. The team also consisted of a training manager (BG), training coordinator and, uniquely, a physician lead (JP) with 50-75\% salary support for the duration of the implementation, who oversaw all provider education and communication. The physician lead worked closely with the training manager and IDs to determine the structure, content, and logistics of provider training. Training team roles and responsibilities are further outlined in $>$ Table 1 .

\subsection{Curricular Development}

The training team created provider tracks based upon role and common workflows, e.g. inpatient provider only, ambulatory provider only, obstetric provider, and combined inpatient and ambulatory provider. Tracks consisted of 1-2 instructor-led training classes (5 hours each) and basic e-learning (1 hour total). Eight courses were eligible for continuing medical education (CME) credit, ranging from 4.25 to 5.25 AMA PRA Category 1 Credit $(s)^{\mathrm{TM}}$ credits based upon the class duration. Provider courses, class duration and CME information are presented in Table 2. 
Based upon provider surveys, approximately $20 \%$ of providers (particularly trainees who rotate through the adult hospital) had experience using the new software at other institutions; therefore, accelerated coursework was created for certain provider tracks. The accelerated coursework was 2.5 hours in duration with an emphasis on the features and workflows specific to SCH, assuming competence with the core software features. To qualify for accelerated coursework, providers identified themselves via a brief online survey asking them to attest to duration and location of usage and participation in previous training. The attestation survey was available for two months, with a deadline of 6 weeks prior to the start of training registration ( $>$ Figure 1$)$. The accelerated coursework did not qualify for CME credit, as the learning objectives could not be accomplished in the shortened timeframe. It was also determined that CME training for the full course incentivized those providers who were torn between participating in the accelerated and standard coursework. In addition, participation in the accelerated track exempted providers from completion of the associated e-learning which reviewed the software basics.

In response to feedback from hospital departmental and division leaders, residents and fellows who were based at the adjacent adult hospital, and deemed proficient with a different institutionspecific version of the same software, satisfied their training requirement with e-learning only. This was the only group that did not have a classroom-training requirement. Given their extensive experience with the new EMR, limited clinical time spent at $\mathrm{SCH}$, and demanding clinical schedules, clinical leadership of the implementation project agreed that e-learning was the most appropriate strategy for these learners. The training team created a specific set of e-learning modules for this population, which totaled approximately 1 hour in duration.

\subsection{Course Assignment \& Registration}

The training team assigned providers the appropriate coursework via an institutional learning management system (LMS). This LMS was already in place for existing institutional training purposes and was leveraged for training registration and e-learning delivery. Providers who attested to extensive experience with the EMR were assigned accelerated coursework; others were assigned coursework based upon on their specialty (Pediatrics, OBGYN, Anesthesia, Radiology) and workflow (Inpatient, Ambulatory). For example, a Pediatric Surgeon would be assigned Pediatric Surgical Provider (5 hours) and Ambulatory Provider ( 5 hours). The physician lead for the training team identified the appropriate coursework for each division based upon general knowledge of specialty workflow and based upon communication with each department/division representatives. Training registration began 4 months prior to beginning of the training period. Providers logged into the LMS to select a class date and time during the training period for each classroom activity to which they were assigned. Classroom training was offered Monday through Saturday from 7AM to 7PM on a variety of days each week, with both morning and afternoon classes to accommodate a wide range of clinical schedules. Although providers were encouraged to register by the beginning of the training period, registration remained open throughout the training period for rescheduling purposes. The training manager produced weekly registration reports to determine unregistered providers. The physician lead distributed the lists to department chairs and division chiefs via email to ensure that all providers register for training.

\subsection{Classroom Training}

End-user training took place over an 8-week period in the two months prior to go-live. Classroom training was conducted in the skyboxes of the Stanford University football stadium. This was a nontraditional training venue; however, it was close in proximity to $\mathrm{SCH}$, large enough to accommodate clinical end-user training, and featured an abundance of parking and public transportation options. This location created a fun and inspirational learning environment with space for all classrooms, a helpdesk, and indoor and outdoor space for dining (see photos supplement). Breakfast, lunch, snacks and beverages were provided daily to all participants.

Fifteen distinct provider courses were taught with a total of 215 classroom sessions offered to providers. The program consisted of 18 trainers for provider coursework, including two faculty physicians, six medical students from Stanford University School of Medicine and four IDs from the 
training team. The remaining trainers were hired outside of Stanford Children's Health. These "external" trainers were consultants who had experience teaching the software at other institutions. They joined the project 6 weeks prior to the start of classroom training, during which time they received instruction on adult learning theory, learned the SCH-specific workflows and software customization, finalized the curriculum, and prepared for classroom sessions [21].

The curricular content for each class was structured in a case-based fashion, highlighting the core clinical workflow elements and identifying changes from the prior system ( Table 3 ). The curriculum was presented to the learners via slide presentations and paper supplemental materials. Each classroom was outfitted with one desktop computer and 24-inch monitor per student, as well as two large screens at the front of the classroom, one for the slide presentation, the other to demonstrate the instructor's actions in real-time within the training environment. After a brief introduction to the course objectives, outline, and classroom ground rules, learners were instructed to log into the training environment at their computer terminal. The learners followed along with the instructor walking through each step of the workflow - described verbally, displayed in a written stepwise fashion via PowerPoint, and demonstrated in real-time in the instructor's training environment. The curriculum was instructor-led, punctuated by independent exercises during which students completed a workflow based upon written instructions.

Provider classrooms had a range of 6 to 18 students with a super-user to end-user ratio of 1 to 6 . Classroom support super-users consisted of faculty, fellows, residents, and medical students from Stanford University, who staffed $100 \%$ of all provider classes. In total, approximately 1,220 providers were trained in the classroom, including 550 faculty, 250 community physicians, 160 Advanced Practice Providers (APPs), 100 fellows and 160 residents. E-learning only was assigned to approximately 750 Stanford University-based residents and fellows.

At the conclusion of each class, participants completed an evaluation of the course and a multiple-choice proficiency exam. Upon completion of these tasks, the participants logged into the production environment to test their login credentials and set basic preferences prior to go-live, such as patient list formation, order favorites and note template favorites. Members of the Information Services (IS) security team staffed a helpdesk at the training location during training hours to help with login issues in the production environment. There was also a general helpdesk set up for participants who had further questions outside of classroom hours.

\subsection{Provider Preference Labs}

Two weeks prior to go-live, provider preference labs were held Monday through Friday from 11AM to 7PM. Staffed by credentialed trainers and classroom support super-users, these drop-in labs allowed providers to get more practice using the system, set preferences, learn more about mobile device and remote access, and to ask questions. Over 175 providers took advantage of this opportunity. Although no formal survey was administered, anecdotal comments regarding the preference lab sessions revealed that providers felt the sessions provided more time to:

1. practice using the new system,

2. create favorites and user-specific customizations and

3. gain the confidence they felt necessary to get through their first workday using the software.

\section{Results}

All training participants were asked to complete a 10 question evaluative survey upon completion of their course. The training manager developed the survey, which the training team utilized to evaluate every classroom session during the training period. In the survey, providers assessed their overall experience, including: trainer preparedness, course design, handouts, and the learner's overall readiness to use the system, as a 1 (Poor), 2 (Fair), 3 (Good) or 4 (Excellent). Out of a total of 1,218 providers who attended classroom training, 1,013 completed all survey questions with an $83 \%$ response rate. Mean responses ranged from 3.27 to 3.87 on the 4-point scale ( Table 4). Evaluation of the instructor's mastery of the subject demonstrated the highest score with an average of 3.87. Evaluation of the provider's comfort level with using the system demonstrated the lowest score, which an aver- 
age of 3.27. The survey allowed participants to provide additional comments. 433 additional comments were recorded and overall themes were created from repeat comments. These general themes and example comments are presented in $>$ Table 5.

\section{Discussion}

Physician training is an essential element of EMR actualization; however, there are few concrete recommendations in the literature regarding the development of such a program [3, 6, 8-13]. At Stanford Children's Health, an EMR training program for physicians was developed and implemented prior to a large scale EMR implementation which was considered successful based upon learner evaluation data and feedback from departmental and institutional leadership. Key factors in the success of this training program included a well-staffed training team, a dedicated physician champion, thoughtful curricular design, an accessible and comfortable training location and physician recognition for participation in training. Based upon participant feedback and institutional experience, we have compiled best practice recommendations for future physician training programs.

\subsection{Physician Engagement/Communication}

Our first recommendation is to engage the medical staff in the target organizational change. This is important whether the change entails a large-scale EMR go-live or smaller functionality rollout, both of which require some form of end-user training. One of the best ways to achieve this engagement is to include key physicians to inform the software configuration, testing, and training process, and also serve as liaisons for communication changes to the medical staff. These "physician champions" are usually funded via a reduction in their clinical time, which can vary from $10-50 \%$ full time equivalents (FTE). A total of 22 physician champions were funded for the described project and expected to participate as super-users for classroom support, provider preference labs, and go-live support, among other responsibilities. The success of the training program was also attributed to a dedicated physician lead for training, separate from the role of the Chief Medical Information Officer. This physician provided essential review of clinical context (training patients, training scenarios) and knowledge of institutional workflows (e.g. number of distinct provider workflows, how to group providers in class). In addition, the physician lead was involved in the design and delivery of training communication for both hospital and medical staff leadership. It is important that the physician in this role have an interest in education or curricular design, institutional knowledge, and good communication skills.

Communication focused on the new EMR training requirements are of particular importance, as attending training sessions may represent the end-user's first interaction with the new system. Therefore, the timing, duration and structure of the EMR training should be communicated in advance to the medical staff. For large-scale go-lives, such messages may start up to one year in advance and progress to include incrementally more information as the change approaches. Appropriate forums for presentations include hospital, division and departmental meetings. Written communications can be delivered via medical staff newsletters, email and website postings.

\subsection{Timing}

For larger scale go-lives, training classes should be offered 2 to 8 weeks prior to the change. Training which occurs greater than 8 weeks in advance will likely not be remembered by the end-user. However, this must be balanced with allowing enough time to schedule all courses necessary for a large medical staff. Furthermore, a one-to-two week hiatus prior to go-live is recommended for emergent rescheduling/make-up sessions, remediation, personalization and use of a practice domain.

\subsection{Learning Environment}

Classroom training should occur in a location as close to a provider's clinical practice setting as possible. This proximity allows ease of class scheduling and helps to ensure that providers will arrive on 
time. If the training is not within walking distance, parking and transportation options should be available and ideally without cost. Complimentary meals, snacks and beverages are important to consider, especially for classes greater than two hours in duration. The learning environment should be as conducive to training as possible with consideration given to screen size, ergonomics of workstations, room temperature and external noise reduction.

\subsection{Curricular Design Considerations}

\subsubsection{Learner Groups}

As with any type of curricular development, it is important to know your learner [22]. The training leadership should consider the number of distinct workflows in the population, in order to determine when learners can be grouped together and where the workflow is unique enough to create a different class or track. Classes applicable to a greater breadth of learners can be offered more frequently to accommodate the variable schedules of providers. In addition, repetition of a more general class will allow the trainers to master the delivery of content, improving quality and consistency of core concept delivery during classroom events. Frequently end-users will request classroom training for their division/department exclusively, which may be warranted when the workflow or patient population is highly specialized or unique, but may not always be feasible. Overall, we strongly recommend that coursework should be designed to group learners by common workflow. By clustering medical staff based upon their workflows, it is also easier to maintain physician engagement. For example, those who spend most of their day in the operating room may not be as engaged in classroom training which emphasizes admission, rounding, consultation, and discharge of medical patients.

\subsubsection{Ensuring Clinical Relevance}

One additional way to enhance engagement is to create practice patients for the EMR training domain, which have a variety of diagnoses, mirroring those seen by medical staff throughout the institution. The curriculum should then be delivered through the lens of relevant practice patients, with scenarios that will mimic the learner's workflow. For example, if surgeons are grouped together for classroom training, the curriculum can emphasize pre-operative preparation, booking the operating room, procedure documentation, and post-operative care of a practice patient with a surgical diagnosis such as appendicitis. Although not all learners will perform appendectomies, common surgical workflow is still emphasized. For further instruction or practice, learners can conclude the session by working through an independent exercise with a practice patient and scenario consistent with their sub-specialty practice. A sample outline of the Inpatient Medical Provider coursework is displayed in Table 3.

\subsubsection{Content Delivery Considerations}

Next, the previous EMR experience of the end-users should be considered in order to determine the appropriate duration and delivery of content. The two major types of training utilized for physicians are classroom-based instructor-led training (ILT) and online e-learning. The balance between classroom and e-learning is highly specific to the institution, the EMR, and the desire of the medical staff. E-learning is helpful for basic review of the structure and function of the EMR, whereas complex concepts, multi-step workflows and specialty-specific information are best taught in the classroom. Furthermore, the classroom can be the best place to maintain interaction/enthusiasm, provide individualized assistance, assess competency and create a remediation plan if needed. More often, a training program will consist primarily of classroom training, with a few e-learning modules that review either basic concepts for a general audience or highly specialized concepts that are applicable to a small group of users.

\subsubsection{Enforcing Training Requirement}

Another decision to be made by an organization is whether or not the physician training should be required prior to obtaining security access to the new EMR. The benefits of a requirement include consistency of end-user knowledge base and the reinforcement that the proper training is required to achieve desired efficiency and patient safety. 


\subsubsection{Applying Adult Learning Theory}

Coursework should be based upon adult learning theory and resonate with multiple learning styles. Therefore, whichever classification scheme of learning styles the organization chooses to adopt, careful planning must be incorporated so that all types of learners are reached. The program described above included interactive use of the system, visual cues on classroom monitors and printed handouts, and verbal instructions.

\subsection{Instructor Selection}

It is important to select course instructors who not only have a mastery of the software, but who are engaging professionals trained in the above mentioned adult learning theory and classroom management. Additionally, we found that utilizing instructors with a clinical background was particularly well-received by the learners due to their understanding of the larger clinical context [21].

\subsection{Assessment of Proficiency}

There are two general forms of proficiency assessment: exam-based and demonstration-based. Exam-based assessment, such as multiple-choice questions, can be graded quickly but may not provide an accurate assessment of the end-user's knowledge. Demonstration-based assessment requires 1:1 proctoring as the end-user demonstrates specific tasks to the examiner. This format requires more time and staff for administration; however, it may provide a more accurate assessment of proficiency and allow for immediate remediation. The program described above utilized an exambased assessment but had super-users circulating to room to grade exams on the spot and provide remediation/assistance as needed.

\subsection{Recognition}

As medical staff training will likely take place during a physician's non-clinical time, and other financial incentives may not be feasible, recognition of the time spent training can be awarded via CME credits. The training program described above qualified 4.25 credits per 5 hours session, for a maximum of 14.0 AMA PRA Category 1 Credit(s) ${ }^{\mathrm{TM}}$ designated by Stanford University School of Medicine.

\subsection{Other Considerations and Future Directions}

The training program described above was considered successful based upon provider and institutional feedback at the conclusion of the training period. However, it is important to continually assess the efficacy of initial training, as well to address ongoing training needs, after initial system implementation. Data that could be analyzed to this end could include post go-live training surveys, delinquent physician documentation, incident reports, patient safety indicators and system change requests. Our institution has begun to analyze these factors and to offer efficiency sessions for providers to improve their use of the system. These metrics are not available for inclusion in this case report, but could be a future addition to the literature. In addition, this case report represents one institution's experience with provider training which may limit our ability to predict success in other settings. Lastly, some may argue that with more intuitive software design, the need for provider training should be minimal. Although we agree that it is important to improve software usability, the complexity of clinical workflow and risks to patient safety are too substantial to eliminate provider training programs altogether.

\section{Conclusion}

End-user training for physicians and other medical providers must be deliberate and comprehensive to ensure successful implementation, actualization, end-user satisfaction and appropriate usage of 
the EMR. Failure to do so may result in patient safety, quality, and efficiency issues, as well as physician dissatisfaction. Important aspects to consider are physician engagement, timing, curricular design, assessment of proficiency, and recognition.

\section{Conflict of Interest}

The authors have no conflict of interest to report.

\section{Human Subjects Protection}

The Stanford University Institutional Review Board (IRB) determined this project to be exempt from further review as this activity did not meet the definition of research.

\section{Acknowledgements}

The authors would like to acknowledge Vickey Weir, BSN, MPA and Warren Chandler, for their support of the physician training program. Supplemetary photos: permissions obtained prior to publication. 


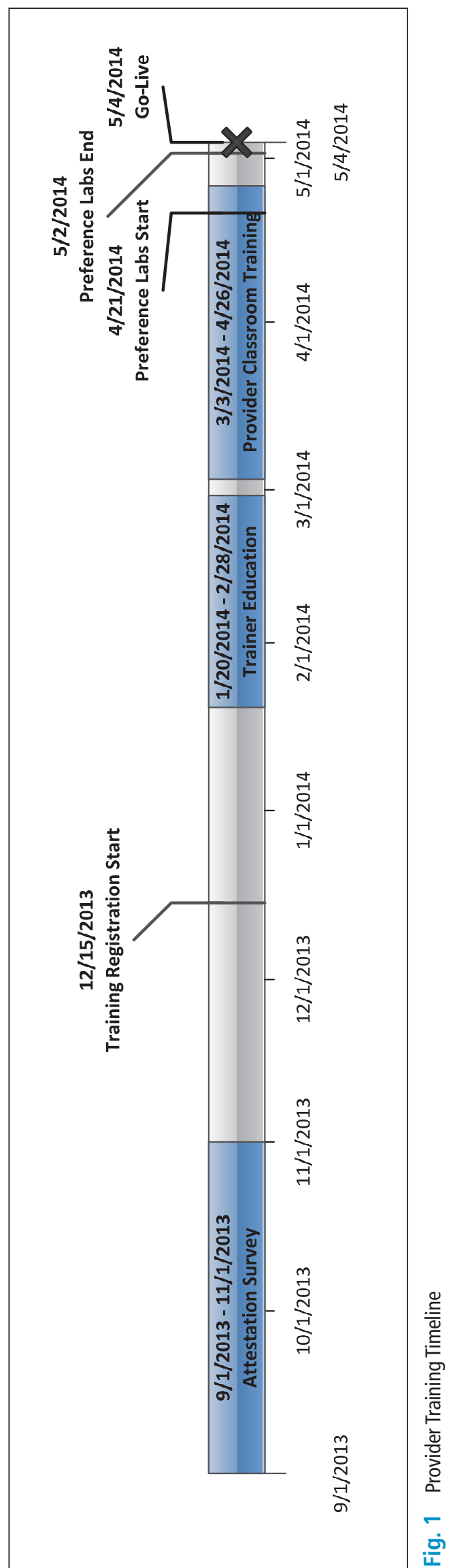


Table 1 Training Team Roles and Responsibilities

\begin{tabular}{|c|c|}
\hline Role & Responsibilities \\
\hline Training Manager & $\begin{array}{l}\text { - Hires and manages IDs, training coordinator, end-user trainers and classroom } \\
\text { super-users } \\
\text { - Manages training timeline and budget } \\
\text { - Communicates with project and hospital leadership } \\
\text { - Oversees training environment development } \\
\text { - Coordinates training material creation and standardization } \\
\text { - Creates LMS reports } \\
\text { - On-site management during training period }\end{array}$ \\
\hline $\begin{array}{l}\text { Physician Lead for } \\
\text { Provider Education }\end{array}$ & $\begin{array}{l}\text { - Works closely with training manager and IDs to: } \\
\text { - Create an overall structure of provider coursework (standard v. accelerated } \\
\text { track, number of hours, number of courses, provider groupings) } \\
\text { - Assign coursework to provider groups } \\
\text { - Create clinically relevant training patients and scenarios } \\
\text { - Review all provider training content (PowerPoint, e-learning, supplemental ma- } \\
\text { terials) } \\
\text { - Designs and delivers training communication to medical and hospital staff leader- } \\
\text { ship } \\
\text { - Manages training involvement of other EMR physician leads and physician class- } \\
\text { room super-users } \\
\text { Serves as course director for CME activities }\end{array}$ \\
\hline Training Coordinator & $\begin{array}{l}\text { - Manages LMS } \\
\text { - Mates master course schedule } \\
\text { - Manages scheduling of end-user trainers and classroom super-users } \\
\text { - Available to providers by phone, email and in person for training questions and } \\
\text { problem-solving }\end{array}$ \\
\hline $\begin{array}{l}\text { Instructional Designers for } \\
\text { Provider Courses (8): } \\
\text { - Ambulatory }-2 \\
\text { - Inpatient }-1 \\
\text { - Obstetrics }-1 \\
\text { - Anesthesia }-1 \\
\text { - Radiology }-1 \\
\text { - Oncology }-1 \\
\text { - Transplant }-1\end{array}$ & $\begin{array}{l}\text { - Integrate/communicate with application teams to translate software features and } \\
\text { workflow into training material } \\
\text { - Create/maintain all training content } \\
\text { - PowerPoint slides } \\
\text { - E-learning } \\
\text { - Supplemental materials } \\
\text { - Build/test/maintain training environments } \\
\text { - Educate/supervise end-user trainers } \\
\text { - Conduct classroom training }\end{array}$ \\
\hline $\begin{array}{l}\text { End-user Trainers: } \\
\text { - IDs } \\
\text { - External trainers } \\
\text { - Medical students }\end{array}$ & - Conduct classroom training \\
\hline
\end{tabular}


Table 2 List of Provider Courses

\begin{tabular}{|l|c|}
\hline Course & Classroom Hours \\
\hline Inpatient Medical Provider & 5 \\
\hline Inpatient Medical Consultant* & 2.5 \\
\hline Inpatient Surgical Provider & 5 \\
\hline Ambulatory Provider & 5 \\
\hline Ambulatory Psychiatry Provider & 5 \\
\hline Ambulatory Oncology Provider & 5 \\
\hline Inpatient OB Provider & 5 \\
\hline Ambulatory OB Provider & 5 \\
\hline Anesthesia Provider & 6 \\
\hline Pediatric Resident* & 5 \\
\hline inpatient and ambulatory content & \\
\hline Obstetric Resident* & 5 \\
\hline inpatient and ambulatory content & 5.5 \\
\hline Anesthesia Resident* & 2.5 \\
\hline Accelerated Ambulatory Provider & \\
\hline Accelerated Inpatient Medical Provider & \\
\hline Accelerated Inpatient Surgical Provider*^ & 2.5 \\
\hline
\end{tabular}

*not CME eligible; ^ ^no e-learning assigned 
Table 3 Sample Course Outline: Inpatient Medical Provider

\begin{tabular}{|c|c|c|}
\hline Workflow & Clinical Scenario & Outline \\
\hline Admission & $\begin{array}{l}11 \text { year-old female with pneumonia admitted to } \\
\text { Pediatric Wards from Urgent Care Clinic. }\end{array}$ & $\begin{array}{l}\text { - Patient list management } \\
\text { - Chart review } \\
\text { - Problem list maintenance } \\
\text { - Medication reconciliation } \\
\text { - Admission order sets } \\
\text { - History \& Physical creation } \\
\text { - Charge capture for notes }\end{array}$ \\
\hline Rounding & $\begin{array}{l}\text { Patient develops pleural effusion and has more re- } \\
\text { spiratory distress requiring chest tube placement. }\end{array}$ & $\begin{array}{l}\text { - Chart review } \\
\text { - Progress note creation } \\
\text { - Rounding checklist } \\
\text { - Order entry } \\
\text { - Request consultation }\end{array}$ \\
\hline Transfer & $\begin{array}{l}\text { Patient condition worsens before surgeons arrive } \\
\text { and requires transfer to Pediatric Intensive Care Unit } \\
\text { (PICU) }\end{array}$ & $\begin{array}{l}\text { - Transfer orders } \\
\text { - Medication reconciliation } \\
\text { - Transfer note creation }\end{array}$ \\
\hline Bedside Procedure & Chest tube placed in PICU & $\begin{array}{l}\text { - Procedure navigator } \\
\text { - Procedure note creation } \\
\text { - Charge capture for procedures }\end{array}$ \\
\hline Discharge & $\begin{array}{l}\text { A few days later, patient recovers and is ready for } \\
\text { discharge. }\end{array}$ & $\begin{array}{l}\text { - Discharge prescriptions } \\
\text { - Medication reconciliation } \\
\text { - Discharge orders } \\
\text { - Discharge summary creation }\end{array}$ \\
\hline Consultation & $\begin{array}{l}17 \text { year-old female post-op spinal fusion, Ortho } \\
\text { team requests consult for pain, nutrition, anemia. }\end{array}$ & $\begin{array}{l}\text { - Chart review } \\
\text { - Consult note creation } \\
\text { - Blood order sets }\end{array}$ \\
\hline $\begin{array}{l}\text { Operating Room (OR) } \\
\text { Procedure }\end{array}$ & $\begin{array}{l}14 \text { year-old female admitted to PICU and needs } \\
\text { bronchoscopy in the OR }\end{array}$ & $\begin{array}{l}\text { - OR case request } \\
\text { - OR status board } \\
\text { - Procedure navigator }\end{array}$ \\
\hline End of Day Activities & N/A & $\begin{array}{l}\text { - Inbox management } \\
\text { - Messaging } \\
\text { - Cosigning notes } \\
\text { - Handoff tool }\end{array}$ \\
\hline User Preferences & N/A & $\begin{array}{l}\text { - Log in department } \\
\text { - Patient list configuration } \\
\text { - Note template favorites } \\
\text { - Order set favorites }\end{array}$ \\
\hline
\end{tabular}


Table 4 Training Evaluation Results

\begin{tabular}{|l|l|l|l|l|l|l|l|}
\hline Question & Excellent & Good & Fair & Poor & $\begin{array}{l}\text { Total } \\
\text { Answers }\end{array}$ & $\begin{array}{l}\text { Mean } \\
\text { Score }\end{array}$ & Std Dev \\
\hline $\begin{array}{l}\text { Organization of presenta- } \\
\text { tion }\end{array}$ & 889 & 150 & 8 & 1 & 1048 & 3.8387 & 0.3953 \\
\hline $\begin{array}{l}\text { Instructor's mastery of sub- } \\
\text { ject }\end{array}$ & 923 & 127 & 4 & 0 & 1054 & 3.8719 & 0.3454 \\
\hline $\begin{array}{l}\text { Instructor's communication } \\
\text { skills }\end{array}$ & 921 & 118 & 16 & 1 & 1056 & 3.8551 & 0.3998 \\
\hline $\begin{array}{l}\text { Quality of handouts for } \\
\text { class }\end{array}$ & 759 & 224 & 29 & 1 & 1013 & 3.7187 & 0.5151 \\
\hline $\begin{array}{l}\text { Questions answered to } \\
\text { your satisfaction }\end{array}$ & 830 & 203 & 14 & 2 & 1049 & 3.7741 & 0.4615 \\
\hline $\begin{array}{l}\text { Adequate time to cover all } \\
\text { topics }\end{array}$ & 807 & 183 & 50 & 9 & 1049 & 3.7045 & 0.5958 \\
\hline $\begin{array}{l}\text { Course objectives were } \\
\text { clear }\end{array}$ & 901 & 138 & 13 & 0 & 1052 & 3.8441 & 0.3954 \\
\hline $\begin{array}{l}\text { Course objectives were } \\
\text { met }\end{array}$ & 873 & 160 & 13 & 0 & 1046 & 3.8222 & 0.4136 \\
\hline $\begin{array}{l}\text { Content of training was } \\
\text { applicable to my role }\end{array}$ & 793 & 193 & 54 & 12 & 1052 & 3.6797 & 0.6236 \\
\hline $\begin{array}{l}\text { Please rate your comfort } \\
\text { level using Epic }\end{array}$ & 505 & 373 & 168 & 24 & 1070 & 3.2701 & 0.8036 \\
\hline
\end{tabular}


Table 5 Training Evaluation Comments

\begin{tabular}{|c|c|}
\hline Subject matter & Example comments \\
\hline $\begin{array}{l}\text { Training delivery - (e.g. length of training, tim- } \\
\text { ing of training in respect to go-live, pace of } \\
\text { training, use of materials) }\end{array}$ & $\begin{array}{l}\text { "More time assigned for classes" } \\
\text { "Decrease class time - it went way over effective learning } \\
\text { time" } \\
\text { "Content was dense - break up into smaller sessions" } \\
\text { "Move training closer to start date" } \\
\text { "Would be nice to do this online due to limited attention } \\
\text { span" } \\
\text { "Concise, to point, efficiently presented" }\end{array}$ \\
\hline $\begin{array}{l}\text { Training setting - (e.g. food, location, parking, } \\
\text { room temperature, breaks, AV) }\end{array}$ & $\begin{array}{l}\text { "Water bottles in room" } \\
\text { "Thanks for the food!" } \\
\text { "Improve pre-class communication/instructions (email parking } \\
\text { instructions, location of class, etc)" } \\
\text { "Larger projector screens" } \\
\text { "Great venue" }\end{array}$ \\
\hline $\begin{array}{l}\text { Training specificity - (e.g. tailored to role, de- } \\
\text { partment, workflow, user needs) }\end{array}$ & $\begin{array}{l}\text { "Personalize to service provider type" } \\
\text { "Faster, more personalized training" } \\
\text { "Separate people with prior experience to Epic. Also separate } \\
\text { based on clinical roles" } \\
\text { "Too broad - stick to division." } \\
\text { "Thanks for making this specific to psych." } \\
\text { "Greatly appreciated that [the trainer] adapted content to my } \\
\text { experience level and provided extra tips." }\end{array}$ \\
\hline Ongoing training needs & $\begin{array}{l}\text { "Have refreshers once or twice a year" } \\
\text { "I only work at SCH 2x a year so I am worried about additional } \\
\text { support later" } \\
\text { "I need more hands on time" } \\
\text { "I need more practice" }\end{array}$ \\
\hline
\end{tabular}




\section{References}

1. Anderson LK, Stafford CJ. The „big bang“ implementation: not for the faint of heart. Computers in nursing 2002; 20(1): 14-20; quiz -2 .

2. Ash JS, Bates DW. Factors and forces affecting EHR system adoption: report of a 2004 ACMI discussion. Journal of the American Medical Informatics Association: JAMIA 2005; 12(1): 8-12.

3. Brokel JM, Harrison MI. Redesigning care processes using an electronic health record: a system's experience. Joint Commission journal on quality and patient safety / Joint Commission Resources 2009; 35(2): $82-92$.

4. Lorenzi NM, Kouroubali A, Detmer DE, Bloomrosen M. How to successfully select and implement electronic health records (EHR) in small ambulatory practice settings. BMC medical informatics and decision making 2009; 9: 15.

5. McAlearney AS, Robbins J, Hirsch A, Jorina M, Harrop JP. Perceived efficiency impacts following electronic health record implementation: an exploratory study of an urban community health center network. Int J Med Inform 2010; 79(12): 807-816.

6. Terry AL, Thorpe CF, Giles G, Brown JB, Harris SB, Reid GJ, Thind A, Stewart M. Implementing electronic health records: Key factors in primary care. Canadian family physician Medecin de famille canadien 2008; 54(5): 730-736.

7. Whittaker AA, Aufdenkamp M, Tinley S. Barriers and facilitators to electronic documentation in a rural hospital. Journal of nursing scholarship : an official publication of Sigma Theta Tau International Honor Society of Nursing / Sigma Theta Tau 2009; 41(3): 293-300.

8. Rockswold PD, Finnell VW. Predictors of tool usage in the military health system's electronic health record, the Armed Forces Health Longitudinal Technology Application. Military medicine 2010; 175(5): 313-316.

9. Kushinka SA. Training strategies: EHR deployment techniques. California Healthcare Foundation 2010; Issue Brief.

10.Edwards G, Kitzmiller RR, Breckenridge-Sproat S. Innovative health information technology training: exploring blended learning. Computers, informatics, nursing: CIN 2012; 30(2): 104-109.

11. Bredfeldt CE, Awad EB, Joseph K, Snyder MH. Training providers: beyond the basics of electronic health records. BMC Health Serv Res 2013; 13: 503.

12. Abramson EL, Patel V, Malhotra S, Pfoh ER, Nena Osorio S, Cheriff A, Cole CL, Bunce A, Ash J, Kaushal R. Physician experiences transitioning between an older versus newer electronic health record for electronic prescribing. Int J Med Inform 2012; 81(8): 539-548.

13.Longhurst CA, Palma JP, Grisim LM, Widen E, Chan M, Sharek PJ. Using an Evidence-Based Approach to EMR Implementation to Optimize Outcomes and Avoid Unintended Consequences. Journal of healthcare information management: JHIM 2013; 27(3): 79-83.

14. Ajami S, Bagheri-Tadi T. Barriers for Adopting Electronic Health Records (EHRs) by Physicians. Acta informatica medica: AIM: journal of the Society for Medical Informatics of Bosnia \& Herzegovina: casopis Drustva za medicinsku informatiku BiH 2013; 21(2): 129-134.

15. Ford EW, Menachemi N, Phillips MT. Predicting the adoption of electronic health records by physicians: when will health care be paperless? Journal of the American Medical Informatics Association: JAMIA 2006; 13(1): 106-112.

16. Adams ES, Longhurst CA, Pageler N, Widen E, Franzon D, Cornfield DN. Computerized physician order entry with decision support decreases blood transfusions in children. Pediatrics 2011; 127(5): e1112-e1119.

17. Bernstein JA, Imler DL, Sharek P, Longhurst CA. Improved physician work flow after integrating sign-out notes into the electronic medical record. Joint Commission journal on quality and patient safety / Joint Commission Resources 2010; 36(2): 72-78.

18.Longhurst CA, Parast L, Sandborg CI, Widen E, Sullivan J, Hahn JS, Dawes CG, Sharek PJ. Decrease in hospital-wide mortality rate after implementation of a commercially sold computerized physician order entry system. Pediatrics 2010; 126(1): 14-21.

19. Palma JP, Van Eaton EG, Longhurst CA. Neonatal Informatics: Information Technology to Support Handoffs in Neonatal Care. NeoReviews 2011; 2011(12).

20. Chi J, Kugler J, Chu IM, Loftus PD, Evans KH, Oskotsky T, Basaviah P, Braddock CH, 3rd. Medical Students and the Electronic Health Record: „An Epic Use of Time“. The American journal of medicine 2014.

21.Stevens LA, Pantaleoni JL, Longhurst CA. The value of clinical teachers for EMR implementations and conversions. Applied Clinical Informatics 2015; 6: 75-79. 
22. McAlearney AS, Robbins J, Kowalczyk N, Chisolm DJ, Song PH. The role of cognitive and learning theories in supporting successful EHR system implementation training: a qualitative study. Medical care research and review: MCRR 2012; 69(3): 294-315. 